Article

\title{
A Feedback Control Method for Addressing the Production Scheduling Problem by Considering Energy Consumption and Makespan
}

\author{
Jingjing $\mathrm{Xu}^{1}$ and Lei Wang ${ }^{2, *}$ \\ 1 Faculty of Economics and Management, East China Normal University, Shanghai 200241, China; \\ jjxu@bs.ecnu.edu.cn \\ 2 Department of Industrial Engineering and Management, Shanghai Jiao Tong University, \\ Shanghai 200240, China \\ * Correspondence: wlei81@163.com; Tel.: +86-21-3420-6101
}

Received: 13 March 2017; Accepted: 2 July 2017; Published: 6 July 2017

\begin{abstract}
Due to various factors of uncertainty within production, the key performance indicators connected to production plans are difficult to fulfil. This problem becomes especially serious as emission regulations are enforced, which discourage manufacturers from high emission output and high energy consumption. Thus, this paper proposes a feedback control method for the production scheduling problem by considering energy consumption and makespan to help manufacturers keep production implementations in pace with production plans. The proposed method works in a rolling horizon framework, which establishes planned energy consumption and makespan, and adjusts the weights of the multiple scheduling optimization objectives for the next period, based on the feedback of the actual energy consumption and makespan in previous periods. A job shop scheduling case study is provided to illustrate the proposed method. The experiment results demonstrate the effectiveness of the proposed feedback control method.
\end{abstract}

Keywords: energy-aware manufacturing; feedback control; production scheduling; multi-objective optimization

\section{Introduction}

Under the pressure of increasing environmental protection concerns, stricter legislation and rising energy costs, improving energy efficiency in the manufacturing industry has become a critical objective. Meanwhile, the highly competitive market drives manufacturing companies to maintain high levels of productivity by working with traditional production scheduling problems, such as optimizing processing time, cost, etc. As a result, most manufacturing companies are caught in the dual challenge of managing energy consumption (EC) and maintaining production efficiency. At the same time, as information technology, and especially the internet of things (IoT) technology develops and is gradually applied in the manufacturing domain, a lot of detailed information about the manufacturing processes/operations and their relationship with EC becomes available. This enables us to realize energy and production efficient manufacturing by using the low-level manufacturing operation data. In this area, Marzband has completed research [1-11] on algorithms, decision-making methods, control mechanisms, and has contributed an optimal energy management system for smart microgrids. Mourtzis [12,13] studied the cloud-based adaptive process planning and shop-floor scheduling method while considering machine tool status. Fysikopoulos $[14,15]$ made a process planning system for energy efficiency by considering the machine modes. Larreina [16] worked on a smart manufacturing execution system.

However, the challenge that this paper tackles is not solely how to improve the energy and manufacturing efficiency by production planning and scheduling, but it is also concerned with how to 
make and effectively implement the production plan. Due to the many uncertain factors in production, the key performance indicators within production plans are difficult to fulfill as planned. This leads to a disconnection between production practices and production plans, which makes production plans infeasible as actual production processes deviate from production plans. This problem becomes especially serious as emission regulations are enforced, which limits manufacturers' emission output and energy consumption.

Thus, this paper proposes a feedback control method for the production scheduling problem by considering energy consumption and makespan, to help manufacturers keep production implementations in pace with production plans. The proposed method works in a rolling horizon framework. A multi-objective optimization model of a job-shop scheduling problem is used to illustrate the feedback control method. In the method, when the actual value of EC exceeds its predicted value, i.e., one of the shop floor's key performance indicators (KPIs), rescheduling strategies will be activated to modify the production scheduling model parameters of the next period by adjusting the weights of objective functions. Currently, this feedback control scheduling model aims to balance the EC and makespan (MS) by keeping them within the expected boundary, which is an important issue, as more and more manufacturing companies have to face the emission trading scheme (ETS).

The remainder of this paper is organized as follows: Section 2 introduces the contribution of this paper by comparing it with related works. Section 3 presents the feedback control method. The multi-objective optimization model of a job-shop scheduling problem and the corresponding algorithm are provided. Then, a case study is used to validate the proposed method in Section 4 . Section 5 presents the conclusion.

\section{Related Works}

This paper is based on the work from three perspectives as described in the following paragraphs. The first to consider is an energy-aware manufacturing system. By observations from Japan, Europe and the United States, Gutowski et al. [17] pointed out that environmentally benign manufacturing needed systems level thinking and strategic planning. With a case study at an automotive paint shop, [18] showed that EC could be reduced significantly through production system design. Through interviews with industry representatives, Ernst et al. [19] found there was a need for energy efficiency KPIs to track the changes and improvements on both the processes and at the plant level, and the need for the integration of real-time data and knowledge-embedded processes to manage and optimize the energy efficiency of the production processes. Hesselbach et al. [20] presented an energy oriented simulation model for the planning of manufacturing systems, which emphasized dynamic interactions of different processes and auxiliary equipment. Seliger et al. [21] introduced an EnergyBlocks method for accurate EC prediction and indicated that real-time energy consumption data, in combination with integrated scheduling algorithms, would allow for the automated adaptation of the actual production schedule. Kellens et al. [22] also provided a structured approach for energy and resource efficient manufacturing, and noted the importance of planning and control optimization methods. Similar to the above work, the feedback control method in this paper combines actual production process data with production scheduling to realize energy-ware manufacturing by considering the dynamic interaction of EC KPIs with different production planning levels. Moreover, the proposed method adopts control strategies from a temporal perspective by adjusting short-term schedules according to comparison results of actual shop floor data and planned KPIs to make the schedule implementation coincide with the production plan. This will be more important than ever as the emission trading scheme prevails at the company level [23-27].

The second consideration is the EC calculating model. Seow and Rahimifard, Liu et al. and Prabhu et al. [28-30] proposed models for characterizing EC at various levels such as product level, machine level, process level and plant level within manufacturing systems to analyze the spatial and temporal distribution of EC and evaluate the EC of the facilities at the early stages of manufacturing. Kara and Li, Woolley et al. [31,32] presented models to characterize the relationship between EC 
and manufacturing parameters or process variables. In the light of these works, this paper makes the assumption that the actual shop floor EC is calculated based on the above proposed models. Therefore, this paper does not use the EC calculating model, but focuses on analyzing the actual shop floor EC data together with the corresponding predicated values used in the production schedules for generating production control policies.

The last perspective is the EC-related production scheduling and multi-objective dynamic scheduling. There has been growing interest in EC-related scheduling in recent years. Twomey et al. [33] presented one of the most well-known works, in which operational methods and a multi-objective mathematical programming model were proposed to minimize EC and total work completion time. The following researches have focused on controlling peak load [34,35], minimizing electricity costs by considering time-dependent stratified electricity prices [36-38], and reducing overall EC [39-41]. The distinction of this paper is that it treats the EC-related scheduling problem not only as a multi-objective one, but also as a dynamic scheduling problem. In the literature about multi-objective dynamic scheduling, Rossi and Dini, Li and Jiang [42,43] considered new task arrival, temporary part unavailability, and temporary machine breakdown as unexpected events, and proposed event-driven approaches. Fattahi and Fallahi, Li et al. [44,45] discussed the balance between efficiency and the stability of dynamic scheduling problems. Shnits [46] emphasized that the decision criteria for the optimization problem should be changed as the system conditions change. Na and Park [47] dealt with a scheduling problem with multi-level job structures and also pointed out that the scheduling is a short-term planning and controlling activity, and could change frequently in accordance with the production shop status. In this study, the feedback control method adopts similar decision support frameworks as those of [46-50]. As in most of the above research, a genetic algorithm is used in this paper to develop a solution for the scheduling problem. However, this paper distinguishes that the objective function parameters for the production schedule problem are adjusted adaptively, and determined periodically based on actual shop floor status and system priority feedback, besides integrating $\mathrm{EC}$ as one of the objective functions.

\section{The Feedback Control Method}

Traditionally, unexpected events such as machine breakdown or new task arrival, are accepted as the major causes for the actual production progress to be inconsistent with the production plan. In fact, the more common reason is that the parameters, such as operation time, used by various algorithms for generating a production plan, are long-term constant statistical values that cannot reflect the volatility of the actual production status. Furthermore, the traditional planning and scheduling process mostly works in a predictive open-loop manner, which increases the contradictions between the actual production implementation and the plan. Therefore, a feedback control method that emphasizes using the real-time manufacturing operation data in a reactive manner with the higher-level KPIs is presented in this section. In the proposed method, the long-term plan is divided into short-term schedules, which allows the subsequent scheduling to take the actual states in the previous schedules and the deviation from the KPIs of the long-term plan into consideration. A new optimization problem is created for each short-term schedule by adjusting the objective function parameters to make the schedule both operational on the shop floor and also satisfy the KPIs of a higher-level plan in the long-term. In this paper, the objective is to minimize production EC and MS.

\subsection{Framework of the Feedback Control Method}

Figure 1 shows the framework of the proposed method. The inputs are the production task, expected EC and delivery time, which can be regarded as the control reference, i.e., requirements from KPIs of the higher-level plan. The outputs include the short-term schedule, and the planned EC and MS for the corresponding production task. 


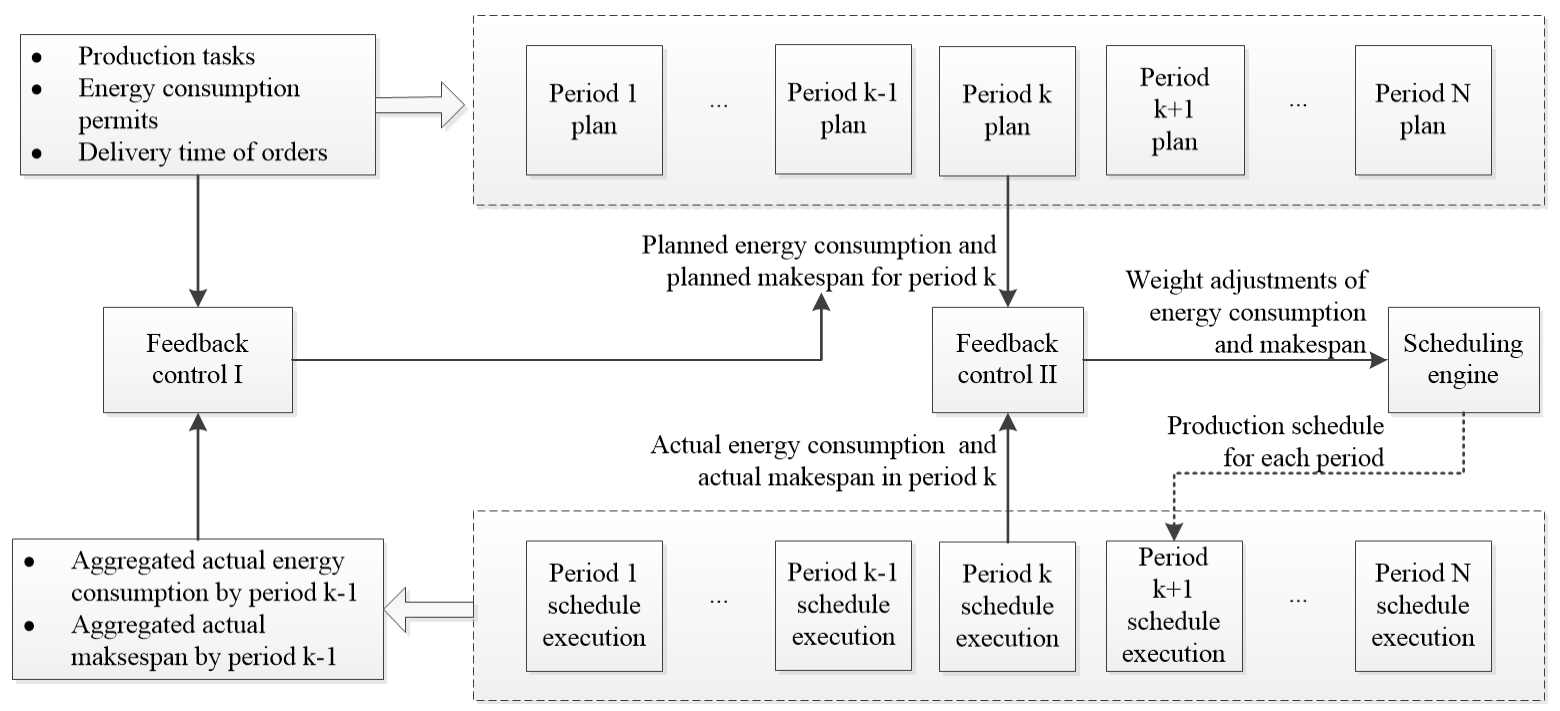

Figure 1. Framework of the feedback control method for the production scheduling problem.

In the proposed method, the long-term production plan horizon is divided into $\mathrm{N}$ periods with equal time intervals. The proposed method contains two feedback control functions and a scheduling engine. The first feedback control compares the aggregated actual EC and MS with the permitted EC and the delivery time of orders, and generates the planned EC and MS, i.e., the KPI requirements for the next phase. The second feedback control function adjusts the weights of the optimization objectives in the next period by considering the gap between the planned EC and MS and the actual EC and MS in the previous period. The scheduling engine is used to solve the multi-objective optimization problem for scheduling the production tasks in each period.

\subsection{Multiple Objectives}

In the feedback control method, two objectives are considered: EC and MS. This multi-objective problem is solved through the combination of the two objectives into a single objective by adding a weighted sum. Thus, the objective function is

$$
\min f\left(w_{1}, w_{2}\right)=w_{1} f_{1}+w_{2} f_{2}=w_{1} \max \left\{C_{1}, C_{2}, \ldots, C_{n}\right\}+w_{2} E w_{1}+w_{2}=1 ; w_{1}, w_{2} \geq 0
$$

$f_{1}$ and $f_{2}$ represent MS and EC respectively. $C_{i}$ is the time when job $i$ is finished. $E$ is the total EC. The weights $w_{1}$ and $w_{2}$ are fundamental to the result of the solution, and are used to adjust the schedule. If the actual EC is bigger than the planned value, $w_{2}$ should be increased to strengthen the weight of EC in the next schedule. Similarly, $w_{1}$ should be increased if the actual MS exceeds the planned value.

\subsection{Safety Threshold}

In order to keep the long-term production plan stabilized, safety thresholds $E_{T}$ and $T_{T}$ are introduced in this method. If the deviation between actual value and planned value is within the safety threshold, the previous schedule should be executed within a controllable boundary. Otherwise, the control strategy will be activated to adjust the weights of the scheduling problem for the next stage.

\subsection{Production Scheduling Process}

The production scheduling process includes the following four steps.

Step 1: The long-term production plan, including both the production task and KPIs of the production plan, is decomposed into $\mathrm{N}$ periods. Herein, the KPIs refer to the total EC, i.e., $E_{I n}$, and 
the total MS, i.e., $T_{I n}$, in which $E_{I n}$ can be taken as the allowed values allocated for this production task. Define $T a_{i}$ as the actual MS in period $i$, and $E a_{i}$ as the actual EC in period $i$. Then, the planned MS for sub-tasks in the $i$ th period is

$$
T_{p}^{i}=\left(T_{I n}-\sum_{j=0}^{i-1} T a_{j}\right) /(N-i+1) T a_{j}=0 ; i=1,2, \ldots, N
$$

and the planned EC in the $i$ th period is

$$
E_{p}^{i}=\left(E_{I n}-\sum_{j=0}^{i-1} E a_{j}\right) /(N-i+1) E a_{j=0}=0 ; i=1,2, \ldots, N
$$

Step 2: A reactive rolling horizon scheduling mechanism is used to realize production scheduling. In each period, a multi-objective optimization model is applied to determine a satisfactory solution for Equation (1).

Step 3: By comparing the actual MS and EC with the corresponding planned values, the control strategy is used to infer the weights $w_{1}^{i+1}$ and $w_{2}^{i+1}$ for the next scheduling period. In this way, a new multi-objective optimization problem is dynamically generated for the next scheduling period based on the actual MS and EC data in the previous periods.

Step 4: Go back to step 2 until period $N$.

\subsection{Control Strategy}

The control strategy is as follows. Define

$$
\Delta T_{i}=T a_{i}-T_{p}^{i}, \Delta E_{i}=E a_{i}-E_{p}^{i}
$$

as the deviations of the actual MS and EC from their planned values in the $i$ th period. Then,

(1) If $\Delta T_{i} \leq T_{T}$ and $\Delta E_{i} \leq E_{T}$, the weight is suitable for the actual production, then $w_{1}^{i+1}=w_{1}^{i}$, $w_{2}^{i+1}=w_{2}^{i}$

(2) If $\Delta T_{i} \leq T_{T}$ and $\Delta E_{i}>E_{T}$, the actual EC exceeds the safety threshold, but the MS is under control, then, $w_{2}^{i+1}=w_{2}^{i}+k_{e} \times \Delta E_{i}, w_{1}^{i+1}=1-w_{2}^{i}$;

(3) If $\Delta T_{i}>T_{T}$ and $\Delta E_{i} \leq E_{T}$, the MS exceeds the safety threshold, but the EC is under control, then $w_{1}^{i+1}=w_{1}^{i}+k_{t} \times \Delta T_{i}, w_{2}^{i+1}=1-w_{1}^{i}$;

(4) If $\Delta T_{i}>T_{T}$ and $\Delta E_{i}>E_{T}$, both the actual MS and EC exceed the safety thresholds, and it requires an analysis of the low-level operation data and the experienced knowledge of workers to infer the weights $w_{1}^{i+1}$ and $w_{2}^{i+1}$. The excess may also be caused by the inappropriate allocation of the planned $T_{p}^{i}$ and $E_{p}^{i}$. In this case, further analysis of the low-level operation data and the experienced knowledge of workers will be necessary.

\subsection{The Multi-Objective Optimization Model}

The multi-objective optimization model is presented to solve the scheduling problem in each period within the feedback control method. Although the feedback control mechanism can be used for various production scheduling problems, different factories face different types of scheduling problems and will require different models. This paper constructs the model for solving a job-shop scheduling problem by considering the optimisation of both MS and EC.

In the job-shop scheduling problem, there are $n$ kinds of jobs. Each job has $m$ operations, which are processed on $m$ machines respectively, but the process sequences are different. The objective is the minimization of both EC and MS. The assumptions are as follows: 
(1) The processing time of each operation of every job is assumed to be known.

(2) For each machine, only one job can be processed on it at one time.

(3) The setup time for each operation is negligible or included in the processing time.

(4) Each operation should be processed on the specified machine which is known, and only after the current operation is finished, could the next operation begin.

(5) Job processing cannot overlap.

(6) Once job processing has begun, it cannot be interrupted.

(7) The jobs' processing times on every machine are not deterministic. They are stochastically generated by following the uniform distribution within a possible range.

(8) The EC for processing, idle, starting up and transportation per unit time can be observed by the monitoring system.

The model of the multi-objective optimization problem is as follows:

$$
\begin{aligned}
\min f_{1}= & \max \left\{C_{i}\right\} i=1,2, \ldots, n ; \\
& \min f_{2}=E
\end{aligned}
$$

Subject to:

$$
\begin{gathered}
C_{i}=\max \left\{C_{i, k}\right\} i=1,2, \ldots, n ; k=1,2, \ldots, m \\
E=\sum_{i=1}^{n} \sum_{k=1}^{m} P_{i, k} \times E p p_{i, k}+\sum_{k=1}^{m} t_{k} \times E s p_{k}+\sum_{h=1}^{n} \sum_{k=1}^{m} t l_{h, k} \times E i p_{k}+\sum_{i=1}^{n} \sum_{o_{i}=1}^{m-1} d_{o_{i}(o+1)_{i}} \times E t p_{i} \\
C_{i, k}-p_{i, k}+M\left(1-\alpha_{i, h, k}\right) \geq C_{i, h} i=1,2, \ldots n ; h, k=1,2, \ldots m \\
C_{i, k}-C_{i, k}+M\left(1-x_{i, h, k}\right) \geq p_{i, h} i, j=1,2, \ldots n ; k=1,2, \ldots m \\
C_{i, k}=p_{i, k}+S_{i, k} i=1,2, \ldots n ; k=1,2, \ldots m \\
t l_{h, k}=S_{(h+1)_{k}, k}-C_{h_{k}, k} h_{k}=1,2, \ldots n ; k=1,2, \ldots m \\
x_{i, j, k}=0 \text { or } 1 i, j=1,2, \ldots n ; k=1,2, \ldots m \\
\alpha_{i, j, k}=0 \text { or } 1 i=1,2, \ldots n ; h, k=1,2, \ldots m
\end{gathered}
$$

$C_{i}$ is the time when job $i$ is finished. $\mathrm{E}$ is the total EC. $M$ is a given, large positive number. $n$ is the number of jobs for processing. $m$ is the number of machines. $p_{i, k}$ is the processing time of job $i$ on machine $k$. $S_{i, k}$ is the time when job $i$ starts to be processed on machine $k . C_{i, k}$ is the time when job $i$ is finished on machine $k . \alpha_{i, h, k}$ is defined as: if job $i$ is processed on machine $h$ earlier than machine $k, \alpha_{i, h, k}=1$; otherwise, $\alpha_{i, h, k}=0$. $x_{i, j, k}$ is defined as: if job $i$ is processed on machine $k$ earlier than job $j, x_{i, j, k}=1$; otherwise, $x_{i, j, k}=0 . E p p_{i, k}$ is the processing EC per unit time of job $i$ on machine $k$. Esp $p_{k}$ is the starting up EC on machine $k$, and $t_{k}$ is the starting up times of machine $k$. Eip $k_{k}$ is the idle EC per unit time on machine $k$, and $t l_{h, k}$ is the idle time of machine $k$ after job $h$ is finished. $h_{k}$ means that the job $h$ is processed on machine $k$. Etp is the transporting EC per unit distance, and $d_{h, k}$ is the distance from machine $h$ to machine $k$.

There are two optimization objectives: Equation (4) means to minimize the MS, and Equation (5) means to minimize the total EC. Equation (7) is for calculating the total EC, which is the sum of the total processing energy, the total starting up energy, the total idle energy and the total energy for transportation. Equation (6) means that the finished time of a job is equal to the maximized completion time of all of its operations. Equation (8) means that a job's next operation cannot be processed until its current operation is finished. Equation (9) means that a machine can process a new job only after it has finished the current one. Equation (10) means that the completion time of job $i$ on machine $k$ is equal to the sum of the starting time and the processing time. Equation (11) means that a machine's idle time is determined by the starting time of the next job and the finishing time of the current job. 
Both $x_{i, j, k}$ and $\alpha_{i, h, k}$ are $0-1$ variables. Equation (12) means that if job $i$ is processed on machine $k$ earlier than job $j$, then $x_{i, j, k}=1$; otherwise, $x_{i, j, k}=0$. Equation (13) means that if job $i$ is processed on machine $h$ earlier than on machine $k$, then $\alpha_{i, h, k}=1$; otherwise, $\alpha_{i, h, k}=0$. As explained in Section 2, a genetic algorithm is used to solve the multi-objective optimization problem.

\section{Case Study}

A job-shop scheduling problem is provided as a case study to validate the feedback control method from three perspectives: effects of the weights in the multi-objective optimization model, the feedback control mechanism, and the safety thresholds.

\subsection{Effect of the Weights}

The weights are the control variables in each period of the feedback control method, which adjust the trade-off between EC and MS in the multi-objective optimization model. In this case study, only idle machine EC is considered for simplifying the calculation, and different problem sizes are discussed for testing the effects of the weights. Tables 1-3 present the processing time, the idle $\mathrm{EC}$ of the machines, and the machine processing sequence of the job-shop scheduling problem with different sizes, respectively.

Table 1. Processing time (minutes).

\begin{tabular}{|c|c|c|c|c|c|c|c|c|}
\hline \multicolumn{9}{|c|}{4 Jobs } \\
\hline & M1 & M2 & M3 & M4 & & & & \\
\hline $\mathrm{J} 1$ & 22 & 45 & 38 & 47 & & & & \\
\hline $\mathrm{J} 2$ & 72 & 45 & 58 & 27 & & & & \\
\hline J3 & 74 & 71 & 65 & 43 & & & & \\
\hline $\mathrm{J} 4$ & 36 & 41 & 43 & 59 & & & & \\
\hline \multicolumn{9}{|c|}{6 Jobs } \\
\hline & M1 & M2 & M3 & M4 & M5 & M6 & & \\
\hline $\mathrm{J} 1$ & 22 & 45 & 38 & 47 & 29 & 59 & & \\
\hline $\mathrm{J} 2$ & 72 & 45 & 58 & 27 & 35 & 65 & & \\
\hline J3 & 74 & 71 & 65 & 43 & 41 & 53 & & \\
\hline $\mathrm{J} 4$ & 36 & 41 & 43 & 59 & 59 & 69 & & \\
\hline J5 & 62 & 49 & 67 & 70 & 56 & 36 & & \\
\hline J6 & 58 & 64 & 37 & 38 & 57 & 56 & & \\
\hline \multicolumn{9}{|c|}{8 Jobs } \\
\hline & M1 & M2 & M3 & M4 & M5 & M6 & M7 & M8 \\
\hline $\mathrm{J} 1$ & 22 & 45 & 38 & 47 & 29 & 59 & 46 & 39 \\
\hline $\mathrm{J} 2$ & 72 & 45 & 58 & 27 & 35 & 65 & 72 & 47 \\
\hline $\mathrm{J} 3$ & 74 & 71 & 65 & 43 & 41 & 53 & 69 & 28 \\
\hline $\mathrm{J} 4$ & 36 & 41 & 43 & 59 & 59 & 69 & 44 & 59 \\
\hline J5 & 62 & 49 & 67 & 70 & 56 & 36 & 21 & 69 \\
\hline J6 & 58 & 64 & 37 & 38 & 57 & 56 & 27 & 59 \\
\hline J7 & 33 & 67 & 50 & 55 & 56 & 61 & 22 & 67 \\
\hline J8 & 59 & 60 & 49 & 62 & 37 & 21 & 30 & 66 \\
\hline
\end{tabular}

Table 4 shows the objective function results $f_{1}$ and $f_{2}$ of the multi-objective optimization model, i.e., the MS and EC values of the job-shop scheduling problem with the sizes of 4,6 , and 8 , under different weights. When the size is 4, the MS and EC values keep invariant despite drastic changes of their weights. When the size is 6 and 8 , decreasing tendencies can be observed in both MS and EC as their corresponding weights $w_{1}$ and $w_{2}$ increase. The explanation for this is that there are fewer combinations of the job sequences when the size is small, e.g., 4 , while there are more combinations of the job sequences when the size gets bigger, e.g., 6 or 8 . In other words, there is increased adjustment 
space as the problem size increases. This may indicate that the weight adjustment has stronger effects on a bigger sized problem.

Table 2. Idle energy consumption (EC) (KJ per minute).

\begin{tabular}{ccccccccc}
\hline \multicolumn{7}{c}{ 4 Jobs } \\
\hline EC & M1 & M2 & M3 & M4 & & & & \\
\hline & & 28 & 23 & 30 & & & & \\
\hline & M1 & M2 & M3 & M4 & M5 & M6 & & \\
\hline EC & 11 & 28 & 23 & 30 & 16 & 38 & & \\
\hline & & & & $\mathbf{8}$ Jobs & & & & \\
\hline & M1 & M2 & M3 & M4 & M5 & M6 & M7 & M8 \\
\hline EC & 11 & 28 & 23 & 30 & 16 & 38 & 29 & 24 \\
\hline
\end{tabular}

Table 3. Machine processing sequence.

\begin{tabular}{|c|c|c|c|c|c|c|c|c|}
\hline \multicolumn{9}{|c|}{4 Jobs } \\
\hline & O1 & $\mathrm{O} 2$ & $\mathrm{O} 3$ & $\mathrm{O} 4$ & & & & \\
\hline $\mathrm{J} 1$ & M1 & M4 & M3 & M2 & & & & \\
\hline $\mathrm{J} 2$ & M2 & M3 & M1 & M4 & & & & \\
\hline J3 & M4 & M1 & M3 & M2 & & & & \\
\hline $\mathrm{J} 4$ & M3 & M1 & M2 & M4 & & & & \\
\hline \multicolumn{9}{|c|}{6 Jobs } \\
\hline & O1 & $\mathrm{O} 2$ & $\mathrm{O} 3$ & $\mathrm{O} 4$ & O5 & O & & \\
\hline $\mathrm{J} 1$ & M1 & M4 & M3 & M2 & M6 & M5 & & \\
\hline $\mathrm{J} 2$ & M4 & M5 & M1 & M2 & M3 & M6 & & \\
\hline J3 & M6 & M1 & M3 & M2 & M5 & M4 & & \\
\hline $\mathrm{J} 4$ & M3 & M1 & M2 & M4 & M5 & M6 & & \\
\hline J5 & M6 & M5 & M1 & M3 & M2 & M4 & & \\
\hline J6 & M5 & M1 & M6 & M2 & M3 & M4 & & \\
\hline \multicolumn{9}{|c|}{8 Jobs } \\
\hline & O1 & $\mathrm{O} 2$ & $\mathrm{O} 3$ & $\mathrm{O} 4$ & O5 & O6 & O7 & O8 \\
\hline $\mathrm{J} 1$ & M1 & M4 & M3 & M2 & M6 & M7 & M5 & M8 \\
\hline $\mathrm{J} 2$ & M4 & M5 & M8 & M2 & M3 & M6 & M7 & M1 \\
\hline $\mathrm{J} 3$ & M6 & M7 & M3 & M2 & M5 & M8 & M1 & M4 \\
\hline $\mathrm{J} 4$ & M3 & M1 & M2 & M7 & M8 & M6 & M4 & M5 \\
\hline J5 & M6 & M5 & M1 & M8 & M7 & M4 & M3 & M2 \\
\hline J6 & M7 & M1 & M6 & M8 & M3 & M4 & M5 & M2 \\
\hline J7 & M8 & M3 & M2 & M6 & M7 & M5 & M1 & M4 \\
\hline J8 & M4 & M3 & M7 & M8 & M2 & M5 & M1 & M6 \\
\hline
\end{tabular}

Moreover, in Table 4, neither MS nor EC monotonically decrease along with increasing $w_{1}$ or $w_{2}$, although decreasing patterns can be found between MS, EC and their weights. This is due to the genetic algorithm used in the multi-objective optimization model. Genetic algorithm is a search heuristic that may have a tendency to converge towards local optima, or even arbitrary points, rather than the global optimum of the problem. Nevertheless, the results can testify to the role of weight adjustment in the proposed feedback control method. Future work will be focused on finding new optimization algorithms that are more apt to rebalance multiple objectives by weight adjustment. 
Table 4. Optimization results under different weights.

\begin{tabular}{|c|c|c|c|c|c|c|c|c|c|c|c|}
\hline \multicolumn{12}{|c|}{4 Jobs } \\
\hline No. & $w_{1}$ & $w_{2}$ & $f_{1}$ & $f_{2}$ & $f$ & No. & $w_{1}$ & $w_{2}$ & $f_{1}$ & $f_{2}$ & $f$ \\
\hline 1 & 1 & 0 & 289 & 5269 & 289 & 13 & 0.93 & 0.074 & 289 & 5269 & 658.676 \\
\hline 2 & 0.995 & 0.056 & 289 & 5269 & 582.619 & 14 & 0.92 & 0.08 & 289 & 5269 & 687.4 \\
\hline 3 & 0.99 & 0.004 & 289 & 5269 & 307.186 & 15 & 0.91 & 0.088 & 289 & 5269 & 726.662 \\
\hline 4 & 0.985 & 0.01 & 289 & 5269 & 337.355 & 16 & 0.9 & 0.11 & 289 & 5269 & 839.69 \\
\hline 5 & 0.98 & 0.13 & 289 & 5269 & 968.19 & 17 & 0.85 & 0.118 & 289 & 5269 & 867.392 \\
\hline 6 & 0.975 & 0.064 & 289 & 5269 & 618.991 & 18 & 0.8 & 0.124 & 289 & 5269 & 884.556 \\
\hline 7 & 0.97 & 0.028 & 289 & 5269 & 427.862 & 19 & 0.75 & 0.15 & 289 & 5269 & 1007.1 \\
\hline 8 & 0.965 & 0.044 & 289 & 5269 & 510.721 & 20 & 0.7 & 0.165 & 289 & 5269 & 1071.685 \\
\hline 9 & 0.96 & 0.084 & 289 & 5269 & 720.036 & 21 & 0.65 & 0.26 & 289 & 5269 & 1557.79 \\
\hline 10 & 0.955 & 0.072 & 289 & 5269 & 655.363 & 22 & 0.6 & 0.4 & 289 & 5269 & 2281 \\
\hline 11 & 0.95 & 0.036 & 289 & 5269 & 464.234 & 23 & 0.5 & 0.5 & 289 & 5269 & 2779 \\
\hline 12 & 0.94 & 0.024 & 289 & 5269 & 398.116 & 24 & 0 & 1 & 289 & 5269 & 5269 \\
\hline \multicolumn{12}{|c|}{6 Jobs } \\
\hline No. & $w_{1}$ & $w_{2}$ & $f_{1}$ & $f_{2}$ & $f$ & No. & $w_{1}$ & $w_{2}$ & $f_{1}$ & $f_{2}$ & $f$ \\
\hline 1 & 1 & 0 & 515 & 19145 & 515 & 13 & 0.97 & 0.03 & 562 & 16908 & 1796.332 \\
\hline 2 & 0.999 & 0.001 & 515 & 18681 & 1560.621 & 14 & 0.96 & 0.04 & 562 & 16908 & 1892.16 \\
\hline 3 & 0.998 & 0.002 & 515 & 18681 & 588.694 & 15 & 0.95 & 0.05 & 557 & 17370 & 2036.544 \\
\hline 4 & 0.997 & 0.003 & 521 & 18819 & 707.627 & 16 & 0.9 & 0.1 & 562 & 16908 & 2360.06 \\
\hline 5 & 0.996 & 0.004 & 515 & 18681 & 2941.47 & 17 & 0.88 & 0.12 & 562 & 16908 & 2490.828 \\
\hline 6 & 0.995 & 0.005 & 515 & 18681 & 1708.009 & 18 & 0.87 & 0.13 & 562 & 16908 & 2588.904 \\
\hline 7 & 0.994 & 0.006 & 552 & 16955 & 1023.428 & 19 & 0.85 & 0.15 & 562 & 16908 & 3013.9 \\
\hline 8 & 0.993 & 0.007 & 515 & 18681 & 1333.359 & 20 & 0.83 & 0.17 & 562 & 16908 & 3259.09 \\
\hline 9 & 0.992 & 0.008 & 529 & 18676 & 2093.552 & 21 & 0.7 & 0.3 & 562 & 16908 & 4811.96 \\
\hline 10 & 0.991 & 0.009 & 529 & 18676 & 1868.911 & 22 & 0.6 & 0.4 & 562 & 16908 & 7100.4 \\
\hline 11 & 0.99 & 0.01 & 557 & 17370 & 1176.75 & 23 & 0.5 & 0.5 & 562 & 16908 & 8735 \\
\hline 12 & 0.98 & 0.02 & 557 & 17370 & 962.74 & 24 & 0 & 1 & 562 & 16908 & 16908 \\
\hline \multicolumn{12}{|c|}{8 Jobs } \\
\hline No. & $w_{1}$ & $w_{2}$ & $f_{1}$ & $f_{2}$ & $f$ & No. & $w_{1}$ & $w_{2}$ & $f_{1}$ & $f_{2}$ & $f$ \\
\hline 1 & 1 & 0 & 636 & 27059 & 636 & 13 & 0.96 & 0.04 & 659 & 24611 & 1096.34 \\
\hline 2 & 0.998 & 0.002 & 638 & 26339 & 662.423 & 14 & 0.95 & 0.05 & 664 & 25226 & 1616.56 \\
\hline 3 & 0.996 & 0.004 & 641 & 26342 & 688.846 & 15 & 0.94 & 0.06 & 661 & 24550 & 1967.02 \\
\hline 4 & 0.994 & 0.006 & 645 & 26751 & 718.103 & 16 & 0.92 & 0.08 & 673 & 22929 & 2402.36 \\
\hline 5 & 0.992 & 0.008 & 638 & 26339 & 749.424 & 17 & 0.91 & 0.09 & 660 & 26391 & 2966.62 \\
\hline 6 & 0.99 & 0.01 & 650 & 23803 & 740.804 & 18 & 0.85 & 0.15 & 660 & 26012 & 2837.7 \\
\hline 7 & 0.988 & 0.012 & 650 & 23803 & 765.765 & 19 & 0.8 & 0.2 & 661 & 23210 & 5014.4 \\
\hline 8 & 0.986 & 0.014 & 653 & 26782 & 788.918 & 20 & 0.75 & 0.25 & 661 & 23331 & 7191.1 \\
\hline 9 & 0.984 & 0.016 & 655 & 23075 & 835.903 & 21 & 0.7 & 0.3 & 661 & 22549 & 9367.8 \\
\hline 10 & 0.982 & 0.018 & 655 & 23075 & 834.36 & 22 & 0.6 & 0.4 & 661 & 22428 & 11544.5 \\
\hline 11 & 0.98 & 0.02 & 655 & 23075 & 856.78 & 23 & 0.5 & 0.5 & 661 & 22428 & 15897.9 \\
\hline 12 & 0.97 & 0.03 & 661 & 22428 & 878.67 & 24 & 0 & 1 & 661 & 22428 & 22428 \\
\hline
\end{tabular}

\subsection{Effect of the Feedback Control Mechanism}

The effect of the feedback control mechanism is tested by comparing it with scheduling results without feedback in respect to the deviation of MS and EC from their expected values. The size 8 problem in Table 4 is used here.

The assumption of the problem is described as follows. The expected MS and the EC permit of the long-term plan are 6500 and 250,000 respectively. The long-term plan is divided into ten scheduling periods. Therefore, the expected MS and EC values for each period are: $M S_{e}=650$ and $E C_{e}=25,000$. In each period, the actual MS and EC are generated from normal distributions: $M S_{a}$ is from $N\left(M S_{s}, 7\right)$, $E C_{a}$ is from $N\left(E C_{s}, 2000\right)$, in which $M S_{s}$ and $E C_{s}$ are the $f_{1}$ and $f_{2}$ of the selected scheduling solution, as shown in Table 4 . This means that even though there is no unexpected event, the actual data may 
still deviate from those in the selected scheduling solution due to the variability of the parameters in practical implementation. The quality of the scheduling results is measured by the accumulative deviation of MS and EC from their expected values, which are calculated by:

$$
\begin{gathered}
\Delta M S=\sum_{i=1}^{n}\left(M S_{e, i}-M S_{a, i}\right), n \text { is the period number } \\
\Delta E C=\sum_{i=1}^{n}\left(E C_{e, i}-E C_{a, i}\right), n \text { is the period number }
\end{gathered}
$$

As shown in Table 5, while scheduling without feedback, the planned MS and EC in each period are: $M S_{p}=M S_{e}=650$ and $E C_{p}=E C_{e}=25,000$. From Table 4, the MS and EC values of scheduling solution No.7 or 6 , whose $f_{1}=650$, and $f_{2}=23,903$, are closest to the planned ones. Herein, No.7 scheduling solution is selected to be executed in each period. The total accumulative deviations of MS and EC in the long-term are: $\Delta M S_{t}=-21.31$ and $\Delta E C_{t}=14,925$.

Table 5. Comparison between the traditional scheduling method and the feedback control

\begin{tabular}{|c|c|c|c|c|c|c|c|}
\hline \multicolumn{8}{|c|}{ Traditional Scheduling Method } \\
\hline \multirow{2}{*}{ Period No. } & \multicolumn{2}{|c|}{ Actual Data } & \multicolumn{3}{|c|}{$\begin{array}{l}\text { Scheduling Plan and } \\
\text { Planned MS, EC }\end{array}$} & \multicolumn{2}{|c|}{$\begin{array}{l}\text { Accumulative Deviation } \\
\text { with Expected Value }\end{array}$} \\
\hline & $M S_{a}$ & $E C_{a}$ & No. & $M S_{p}$ & $E C_{p}$ & $\Delta M S$ & $\Delta E C$ \\
\hline 1 & 654.3037 & $23,643.074$ & 7 & 650 & 25,000 & -4.3037 & 1356.926 \\
\hline 2 & 652.9354 & $23,860.521$ & 7 & 650 & 25,000 & -7.2390 & 2496.405 \\
\hline 3 & 648.0338 & $25,315.787$ & 7 & 650 & 25,000 & -5.2728 & 2180.618 \\
\hline 4 & 644.9283 & $22,434.408$ & 7 & 650 & 25,000 & -0.2012 & 4746.210 \\
\hline 5 & 655.4449 & $23,214.082$ & 7 & 650 & 25,000 & -5.6461 & 6532.128 \\
\hline 6 & 653.3379 & $24,842.227$ & 7 & 650 & 25,000 & -8.9840 & 6689.901 \\
\hline 7 & 648.7398 & $22,143.234$ & 7 & 650 & 25,000 & -7.7238 & 9546.667 \\
\hline 8 & 656.0027 & $23,094.805$ & 7 & 650 & 25,000 & -13.7266 & $11,451.862$ \\
\hline 9 & 650.7913 & $24,064.828$ & 7 & 650 & 25,000 & -14.5179 & $12,387.034$ \\
\hline 10 & 656.7875 & $22,462.283$ & 7 & 650 & 25,000 & -21.3054 & $14,924.751$ \\
\hline
\end{tabular}
scheduling method.

\begin{tabular}{|c|c|c|c|c|c|c|c|}
\hline \multicolumn{8}{|c|}{ The total deviations: $\Delta M S=$ Index - Actual $=-21.31 ; \Delta E C=$ Index - Actual $=14,925$} \\
\hline \multicolumn{8}{|c|}{ Feedback Control Scheduling Method } \\
\hline \multirow{2}{*}{ Period No. } & \multicolumn{2}{|c|}{ Actual Data } & \multicolumn{3}{|c|}{$\begin{array}{l}\text { Scheduling Plan and } \\
\text { Planned MS, EC }\end{array}$} & \multicolumn{2}{|c|}{$\begin{array}{l}\text { Accumulative Deviation } \\
\text { with Expected Value }\end{array}$} \\
\hline & $M S_{a}$ & $E C_{a}$ & No. & $M S_{p}$ & $E C_{p}$ & $\Delta M S$ & $\Delta E C$ \\
\hline 1 & 654.3037 & $23,643.074$ & 7 & 650 & 25,000 & -4.3037 & 1356.926 \\
\hline 2 & 639.2677 & $26,424.922$ & 5 & 649 & 25,150 & 6.4287 & -67.996 \\
\hline 3 & 652.2067 & $23,837.922$ & 6 & 651 & 24,991 & 4.2219 & 1094.082 \\
\hline 4 & 655.5632 & $24,989.480$ & 6 & 651 & 25,156 & -1.3413 & 1104.602 \\
\hline 5 & 635.5636 & $26,633.080$ & 5 & 650 & 25,184 & 13.0951 & -528.478 \\
\hline 6 & 654.2048 & $23,396.280$ & 6 & 653 & 24,894 & 8.8903 & 1075.242 \\
\hline 7 & 652.8790 & $23,794.967$ & 6 & 652 & 25,269 & 6.0113 & 2280.275 \\
\hline 8 & 654.1343 & $23,332.523$ & 6 & 652 & 25,760 & 1.8770 & 3947.752 \\
\hline 9 & 655.3791 & $23,549.288$ & 6 & 651 & 26,974 & -3.5021 & 5398.464 \\
\hline 10 & 639.9936 & $27,176.507$ & 5 & 646 & 30,399 & 6.5043 & 3221.957 \\
\hline
\end{tabular}

While scheduling with feedback, the planned MS and EC are calculated by Equations (2) and (3) in Section 3.4. If the safety thresholds for MS and $\mathrm{EC}$ are: $\mathrm{MST}=4, \mathrm{ECT}=1000$, then the control strategy in Section 3.5 works as follows. In the 1st period, since $M S_{p}^{1}=650, E C_{p}^{1}=25,000$, scheduling solution No.7 is selected. The actual data of No.7 execution is: $M S_{a, 1}=654.3037, E C_{a, 1}=23,643.074$. 
The deviations are: $\Delta M S_{1}=4.3037>\mathrm{MST}, \Delta E C_{1}=-1356.926<\mathrm{ECT}$. Thus, $w_{1}^{2}$ should be increased, and the control strategy searches the scheduling solution with bigger $w_{1}$ from the current solution used in Table 4 . Because neither MS $\left(f_{1}\right)$ nor EC $\left(f_{2}\right)$ monotonically decrease along with increasing $w_{1}$ or $w_{2}$, the control strategy also compares the scheduling solutions to the planned MS or EC to decide which scheduling solution should be selected. The selection rules are: (1) If $w_{1}^{i+1}$ should be increased, then the nearest solution with bigger $w_{1}$ and whose $f_{1}$ is smaller than $M S_{p}^{i+1}$ should be selected for the $i+1$ period. (2) If $w_{2}^{i+1}$ should be increased, then the nearest solution with bigger $w_{2}$ and whose $f_{2}$ is smaller than $E C_{p}^{i+1}$ should be selected for the $i+1$ period. Therefore, No.5 solution is selected for the 2 nd period. In the same way, scheduling solutions for the rest periods are determined as shown in Table 5. The total accumulative deviations of MS and EC in the long-term are: $\Delta M S_{f}=6.5$ and $\Delta E C_{f}=3221$.

Therefore, the total accumulative deviations of MS and EC with the feedback control mechanism are much smaller than those without it. This proves that the feedback control method can reduce the contradictions in the actual implementation in the long-term plan by making periodic adjustments based on the analysis of actual low-level data. Thus, it is suitable for solving the production scheduling problem. However, it continues to be difficult to choose an ideal solution from the algorithm results for balancing the trade-off among multiple optimization objectives by considering the changeable real-time information in each period. A human-system interaction based method for solving this problem will be a future focus.

\subsection{Discussion of the Safety Thresholds}

The safety thresholds determine the sensitivity of the feedback control mechanism. If the thresholds are quite small, the feedback control mechanism would be very sensitive. In this case, the resulting frequent schedule changes would be unfavorable to the reality of production, because frequent changes would increase preparation and the workers' adaptation. On the other hand, if the thresholds are big, the feedback mechanism would not work efficiently to control the actual deviation from the planned indicators. In future work, data mining methods will be studied to establish proper safety thresholds by analyzing historical production data from concrete factories.

\section{Conclusions}

This paper proposed a feedback control method for scheduling problems to bridge the gap between long-term, higher-level planning, and lower-level shop floor manufacturing implementation. The key is to dynamically adjust the optimization model parameters based on comparing the actual implementation data with the planned manufacturing performance indicators. This paper further considered EC in applying the feedback control method when realizing energy-aware manufacturing. As more and more countries adopt the emissions trading permit policy to combat environmental problems, the proposed feedback control method will be especially suitable for companies in coping with emission trading.

A case study of a job-shop scheduling problem validated the proposed method. The experiment results in Section 4.1 show that the proposed method has a better performance on a larger problem, because a smaller sized problem has narrower adjustment space. It has also been learned that the algorithm used in the scheduling engine may influence the performance of the feedback control method. Therefore, one future focus will be on finding new optimization algorithms that are more apt to rebalance multiple objectives by weight adjustment. By comparing the feedback control method with the traditional method that excludes feedback, the experiment in Section 4.2 proves the effectiveness of the proposed feedback control method. However, how to properly establish the safety thresholds in the feedback control mechanism is still a challenge to be investigated. Another research objective for the future will be connected to the data mining methods for setting proper safety thresholds by analyzing historical production data. 
The limitation of this paper is that it only presents the method of how to tune the optimization model parameters, but has not given a detailed parameter optimization method. Therefore, future work will focus on a human-system interaction based method to balance multiple optimization objectives, and data mining methods of historical manufacturing data for the optimized establishment of how to trigger the feedback control.

Acknowledgments: The authors would like to thank the Natural Science Foundation of China (NSFC) for sponsoring the research under the grants 61203322 . This research is also partly supported by the Shanghai Committee of Science and Technology (No. 15111103403).

Author Contributions: In this paper, Wang was responsible for the design of the whole paper; $\mathrm{Xu}$ wrote the paper and contributed to design, and validated the proposed method. All authors have read and approved the manuscript.

Conflicts of Interest: The authors declare no conflict of interest.

\section{References}

1. Marzband, M.; Moghaddam, M.M.; Akorede, M.F.; Khomeyrani, G. Adaptive load shedding scheme for frequency stability enhancement in microgrids. Electr. Power Syst. Res. 2016, 140, 78-86. [CrossRef]

2. Marzband, M.; Ghazimirsaeid, S.S.; Uppal, H.; Fernando, T. A real-time evaluation of energy management systems for smart hybrid home microgrids. Electr. Power Syst. Res. 2017, 143, 624-633. [CrossRef]

3. Marzband, M.; Azarinejadian, F.; Savaghebi, M.; Guerrero, J.M. An optimal energy management system for islanded microgrids based on multiperiod artificial bee colony combined with Markov chain. IEEE Syst. J. 2017, 99, 1-11. [CrossRef]

4. Marzband, M.; Ardeshiri, R.R.; Moafi, M.; Uppal, H. Distributed generation for economic benefit maximization through coalition formation-based game theory concept. Int. Trans. Electr. Energy Syst. 2017, 27, 1-16. [CrossRef]

5. Marzband, M.; Parhizi, N.; Savaghebi, M.; Guerrero, J.M. Distributed smart decision-making for a multimicrogrid system based on a hierarchical interactive architecture. IEEE Trans. Energy Convers. 2016, 31, 637-648. [CrossRef]

6. Marzband, M.; Sumper, A.; Ruiz-Álvarez, A.; Domínguez-García, J.L.; Tomoiagă, B. Experimental evaluation of a real time energy management system for stand-alone microgrids in day-ahead markets. Appl. Energy 2013, 106, 365-376. [CrossRef]

7. Marzband, M.; Sumper, A.; Domínguez-García, J.L.; Gumara-Ferret, R. Experimental validation of a real time energy management system for microgrids in islanded mode using a local day-ahead electricity market and MINLP. Energy Convers. Manag. 2013, 76, 314-322. [CrossRef]

8. Marzband, M.; Ghadimi, M.; Sumper, A.; Domínguez-García, J.L. Experimental validation of a real-time energy management system using multi-period gravitational search algorithm for microgrids in islanded mode. Appl. Energy 2014, 128, 164-174. [CrossRef]

9. Marzband, M.; Javadi, M.; Domínguez-García, J.L.; Moghaddam, M.M. Non-cooperative game theory based energy management systems for energy district in the retail market considering DER uncertainties. IET Gener. Transm. Distrib. 2016, 10, 2999-3009. [CrossRef]

10. Marzband, M.; Parhizi, N.; Adabi, J. Optimal energy management for stand-alone microgrids based on multi-period imperialist competition algorithm considering uncertainties: Experimental validation. Int. Trans. Electr. Energy Syst. 2016, 26, 1358-1372. [CrossRef]

11. Marzband, M.; Yousefnejad, E.; Sumper, A.; Domínguez-García, J.L. Real time experimental implementation of optimum energy management system in standalone Microgrid by using multi-layer ant colony optimization. Int. J. Electr. Power 2016, 75, 265-274. [CrossRef]

12. Mourtzis, D.; Vlachou, E.; Doukas, M.; Kanakis, N.; Xanthopoulos, N.; Koutoupes, A. Cloud-based adaptive shop-floor scheduling considering machine tool availability. In Proceedings of the ASME 2015 International Mechanical Engineering Congress \& Exposition, Houston, TX, USA, 13-19 November 2015.

13. Mourtzis, D.; Vlachou, E.; Xanthopoulos, N.; Givehchi, M.; Wang, L. Cloud-based adaptive process planning considering availability and capabilities of machine tools. J. Manuf. Syst. 2016, 39, 1-8. [CrossRef] 
14. Fysikopoulos, A.; Stavropoulos, P.; Papacharalampopoulos, A.; Calefati, P.; Chryssolouris, G. A process planning system for energy efficiency. In Proceedings of the 14th International Conference on Modern Information Technology in the Innovation Processes of the Industrial Enterprises, Budapest, Hungary, 24-26 October 2012.

15. Fysikopoulos, A.; Pastras, G.; Vlachou, A.; Chryssolouris, G. An approach to increase energy efficiency using shutdown and standby machine modes. In Advances in Production Management Systems. Innovative and Knowledge-Based Production Management in a Global-Local World, Proceedings of the APMS 2014: IFIP Advances in Information and Communication Technology, Ajaccio, France, 20-24 September 2014; Grabot, B., Vallespir, B., Gomes, S., Bouras, A., Kiritsis, D., Eds.; Springer: Berlin/Heidelberg, Germany, 2014; Volume 439, pp. 205-212.

16. Larreina, J.; Gontarz, A.; Giannoulis, C.; Nguyen, V.K.; Stavropoulos, P.; Sinceri, B. Smart manufacturing execution system (SMES): The possibilities of evaluating the sustainability of a production process. In Proceedings of the 11th Global Conference on Sustainable Manufacturing, Berlin, Germany, 23-25 September 2013; pp. 517-522.

17. Gutowski, T.; Murphy, C.; Allen, D.; Bauer, D.; Bras, B.; Piwonka, T.; Sheng, P.; Sutherland, J.; Thurston, D.; Wolff, E. Environmentally benign manufacturing: Observations from Japan, Europe and the United States. J. Clean. Prod. 2005, 13, 1-17. [CrossRef]

18. Guerrero, C.A.; Wang, J.; Li, J.; Arinez, J.; Biller, S.; Huang, N.; Xiao, G. Production system design to achieve energy savings in an automotive paint shop. Int. J. Prod. Res. 2011, 49, 6769-6785. [CrossRef]

19. Bunse, K.; Vodicka, M.; Schönsleben, P.; Brülhart, M.; Ernst, F.O. Integrating energy efficiency performance in production management-Gap analysis between industrial needs and scientific literature. J. Clean. Prod. 2011, 19, 667-679. [CrossRef]

20. Herrmann, C.; Thiede, S.; Kara, S.; Hesselbach, J. Energy oriented simulation of manufacturing systems-Concept and application. CIRP Ann. Manuf. Technol. 2011, 60, 45-48. [CrossRef]

21. Weinert, N.; Chiotellis, S.; Seliger, G. Methodology for planning and operating energy-efficient production systems. CIRP Ann. Manuf. Technol. 2011, 60, 41-44. [CrossRef]

22. Duflou, J.R.; Sutherland, J.W.; Dornfeld, D.; Herrmann, C.; Jeswiet, J.; Kara, S.; Hauschild, M.; Kellens, K. Towards energy and resource efficient manufacturing: A processes and systems approach. CIRP Ann. Manuf. Technol. 2012, 61, 587-609. [CrossRef]

23. Du, S.; Zhu, L.; Liang, L.; Ma, F. Emission-dependent supply chain and environment-policy-making in the 'Cap-and-trade' system. Energy Policy 2013, 57, 61-67. [CrossRef]

24. Sun, J.; Wu, J.; Liang, L.; Zhong, R.Y.; Huang, G.Q. Allocation of emission permits using DEA: Centralised and individual points of view. Int. J. Prod. Res. 2014, 52, 419-435. [CrossRef]

25. Zhang, J.; Zhang, L. Impacts on $\mathrm{CO}_{2}$ emission allowance prices in China: A quantile regression analysis of the Shanghai Emission Trading Scheme. Sustainability 2016, 8, 1195. [CrossRef]

26. Jiang, W.; Liu, J.; Liu, X. Impact of carbon quota allocation mechanism on emissions trading: An agent-based simulation. Sustainability 2016, 8, 826. [CrossRef]

27. Ye, B.; Jiang, J.; Miao, L.; Li, J.; Peng, Y. Innovative carbon allowance allocation policy for the Shenzhen emission trading scheme in China. Sustainability 2016, 8, 3. [CrossRef]

28. Seow, Y.; Rahimifard, S. A framework for modelling energy consumption within manufacturing systems. CIRP J. Manuf. Sci. Technol. 2011, 4, 258-264. [CrossRef]

29. Li, Y.; He, Y.; Wang, Y.; Yan, P.; Liu, X. A framework for characterising energy consumption of machining manufacturing systems. Int. J. Prod. Res. 2014, 52, 314-325. [CrossRef]

30. Jeon, H.W.; Taisch, M.; Prabhu, V. Modelling and analysis of energy footprint of manufacturing systems. Int. J. Prod. Res. 2014, 53, 7049-7059. [CrossRef]

31. Kara, S.; Li, W. Unit process energy consumption models for material removal processes. CIRP Ann. Manuf. Technol. 2011, 60, 37-40. [CrossRef]

32. Seow, Y.; Rahimifard, S.; Woolley, E. Simulation of energy consumption in the manufacture of a product. Int. J. Comput. Integr. Manuf. 2013, 26, 663-680. [CrossRef]

33. Mouzon, G.; Yildirim, M.B.; Twomey, J. Operational methods for minimization of energy consumption of manufacturing equipment. Int. J. Prod. Res. 2007, 45, 4247-4271. [CrossRef]

34. Fang, K.; Uhan, N.; Zhao, F.; Sutherland, J.W. A new approach to scheduling in manufacturing for power consumption and carbon footprint reduction. J. Manuf. Syst. 2011, 30, 234-240. [CrossRef] 
35. Bruzzone, A.A.G.; Anghinolfi, D.; Paolucci, M.; Tonelli, F. Energy-aware scheduling for improving manufacturing process sustainability: A mathematical model for flexible flow shops. CIRP Ann. Manuf. Technol. 2012, 61, 459-462. [CrossRef]

36. Luo, H.; Du, B.; Huang, G.Q.; Chen, H.; Li, X. Hybrid flow shop scheduling considering machine electricity consumption cost. Int. J. Prod. Econ. 2013, 146, 423-439. [CrossRef]

37. Moon, J.; Shin, K.; Park, J. Optimization of production scheduling with time-dependent and machine-dependent electricity cost for industrial energy efficiency. Int. J. Adv. Manuf. Technol. 2013, 68, 523-535. [CrossRef]

38. Moon, J.; Park, J. Smart production scheduling with time-dependent and machine-dependent electricity cost by considering distributed energy resources and energy storage. Int. J. Prod. Res. 2014, 52, 3922-3939. [CrossRef]

39. Dai, M.; Tang, D.; Giret, A.; Salido, M.A.; Li, W.D. Energy-efficient scheduling for a flexible flow shop using an improved genetic-simulated annealing algorithm. Robot. Comput. Integr. Manuf. 2013, 29, 418-429. [CrossRef]

40. He, H.; Li, Y.; Wu, T.; Sutherland, J.W. An energy-responsive optimization method for machine tool selection and operation sequence in flexible machining job shops. J. Clean. Prod. 2014, 87, 245-254. [CrossRef]

41. Pach, C.; Berger, T.; Sallez, Y.; Bonte, T.; Adam, E.; Trentesaux, D. Reactive and energy-aware scheduling of flexible manufacturing systems using potential fields. Comput. Ind. 2014, 65, 434-448. [CrossRef]

42. Rossi, A.; Dini, G. Dynamic scheduling of FMS using a real-time genetic algorithm. Int. J. Prod. Res. 2000, 38, 1-20. [CrossRef]

43. Li, L.; Jiang, Z. Self-adaptive dynamic scheduling of virtual production systems. Int. J. Prod. Res. 2007, 45, 1937-1951. [CrossRef]

44. Fattahi, P.; Fallahi, A. Dynamic scheduling in flexible job shop systems by considering simultaneously efficiency and stability. CIRP J. Manuf. Sci. Technol. 2010, 2, 114-123. [CrossRef]

45. Zhang, L.; Gao, L.; Li, X. A hybrid genetic algorithm and tabu search for a multiobjective dynamic job shop scheduling problem. Int. J. Prod. Res. 2013, 51, 3516-3531. [CrossRef]

46. Shnits, B. Multi-criteria optimisation-based dynamic scheduling for controlling FMS. Int. J. Prod. Res. 2012, 50, 6111-6121. [CrossRef]

47. Na, H.; Park, J. Multi-level job scheduling in a flexible job shop environment. Int. J. Prod. Res. 2014, 52, 3877-3887. [CrossRef]

48. Keller, F.; Schultz, C.; Braunreuther, S.; Reinhart, G. Enabling energy-flexibility of manufacturing systems through new approaches within production planning and control. Procedia CIRP 2016, 57, 752-757. [CrossRef]

49. Beier, J.; Thiede, S.; Herrmann, C. Energy flexibility of manufacturing systems for variable renewable energy supply integration: Real-time control method and simulation. J. Clean. Prod. 2017, 141, 648-661. [CrossRef]

50. Cassettari, L.; Bendato, I.; Mosca, M.; Mosca, R. Energy resources intelligent management using on line real-time simulation: A decision support tool for sustainable manufacturing. Appl. Energy 2017, 190, 841-851. [CrossRef]

(C) 2017 by the authors. Licensee MDPI, Basel, Switzerland. This article is an open access article distributed under the terms and conditions of the Creative Commons Attribution (CC BY) license (http://creativecommons.org/licenses/by/4.0/). 